708

http://dx.doi.org/10.1590/0100-2945-018/14

\title{
DESENVOLVIMENTO DE GELEIA DE UMBU-CAJÁ CONVENCIONAL E DIETÉTICA ${ }^{1}$
}

\author{
ELISETH DE SOUZA VIANA1 $1^{2}$, MARIA EUGÊNIA DE OLIVEIRA MAMEDE ${ }^{3}$, \\ RONIELLI CARDOSO REIS ${ }^{4}$, LEONARDO DIB DE CARVALHO 5 , \\ MÉRCIA DAMASCENO FONSECA ${ }^{6}$
}

RESUMO-O objetivo deste estudo foi desenvolver e caracterizar geleias de umbu-cajá, convencional (com sacarose) e dietética (com xilitol), a partir dos genótipos Suprema e Preciosa. As formulações foram elaboradas com a proporção 1:1, de polpa mais açúcar ou polpa mais xilitol, com $0,5 \%$ de pectina e teor final de sólidos solúveis entre 62 e $65^{\circ}$ Brix. As geleias foram analisadas em relação às suas características físico-químicas ( $\mathrm{pH}$, acidez titulável, sólidos solúveis, açúcares totais, umidade e cor instrumental) e sensoriais (teste de aceitação, preferência e intenção de compra). $O$ teste de aceitação foi realizado por 73 consumidores, por meio de escala hedônica de 9 pontos, avaliando-se os atributos cor, aroma, sabor e textura. As geleias elaboradas com sacarose apresentaram características físico-químicas semelhantes às geleias dietéticas, exceto os teores de açúcares totais que foram inferiores no produto dietético. A geleia convencional, elaborada com o genótipo Suprema, foi preferida para os atributos aroma, sabor e textura, enquanto a geleia convencional, elaborada com o genótipo Preciosa, foi preferida para os atributos cor, aroma e textura. As geleias dietéticas, elaboradas com os dois genótipos, foram as menos preferidas, mas apresentaram índices de aceitação acima de $60 \%$, o que demonstra o potencial dessas geleias para atender públicos específicos.

Termos para indexação: Spondias sp., xilitol, teste de aceitação, mapa de preferência.

\section{DEVELOPMENT AND EVALUATION OF DIETETIC AND CONVENTIONAL JAM OF UMBU-CAJA (SPONDIAS SP.)}

\begin{abstract}
The aim of this study was to develop and evaluate conventional (with sucrose) and dietetics (with xylitol) jam of umbu-caja, from the varieties Suprema and Preciosa. The formulations were prepared with pulp more sugar (1:1) or xylitol more pulp (1:1), both with $0.5 \%$ pectin. The final content of soluble solids ranged from $62-65^{\circ}$ Brix. The jams were analyzed in relation to physico-chemical ( $\mathrm{pH}$, titratable acidity, soluble solids, total sugars, moisture, and instrumental color) and sensorial characteristics (acceptability test and purchase intention). Acceptability test was performed by 73 consumers using a 9-point hedonic scale, evaluating the attributes: appearance, color, aroma, flavor and texture. Jams prepared with sucrose showed physicochemical characteristics similar to dietary jams, except the levels of total sugars which were lower in the dietetic product. The jam made with conventional genotype Supreme was preferred for flavor, taste and texture, while the conventional jam prepared with genotype Preciosa was preferred for the attributes color, aroma and texture. The dietary jellies prepared with the two genotypes were less preferred, but had acceptance rates above $60 \%$, which demonstrates the potential of these jams to meet specific audiences.

Index terms: Spondias sp., xylitol, acceptance testing, preference mapping.
\end{abstract}

'( Trabalho 018-14). Recebido em: 16-01-2014. Aceito para publicação em: 16-04-2015.

${ }^{2}$ Economista Doméstica, D.Sc. Microbiologia Agrícola, pesquisadora da Embrapa Mandioca e Fruticultura. Cruz das Almas - BA. E-mail: eliseth.viana@embrapa.br.

${ }^{3}$ Química, D.Sc. Ciência de Alimentos, Professora Departamento de Análises Bromatológicas, Faculdade de Farmácia, Universidade Federal da Bahia. Salvador - BA. E-mail: mmamede@ufba.br

${ }^{4}$ Engenheira de Alimentos, D.Sc. Ciência e Tecnologia de Alimentos, Pesquisadora da Embrapa Mandioca e Fruticultura. Cruz das Almas - BA. E-mail: ronielli.reis@embrapa.br

${ }^{5}$ Engenheiro de Alimentos, Mestre em Ciência de Alimentos, Empresário, Dubom Industria e Comércio de Alimentos Ltda - Cruz Das Almas, BA. E-mail: leodibcarvalho@hotmail.com

${ }^{6}$ Farmacêutica, Mestranda em Engenharia Ambiental, Universidade Federal Rural de Pernambuco, Recife - PE. E-mail: mercia. fonseca@gmail.com

Rev. Bras. Frutic., Jaboticabal - SP, v. 37, n. 3, p. 708-717, Setembro 2015 


\section{INTRODUÇÃO}

A umbu-cajazeira é uma espécie nativa do Nordeste brasileiro, tolerante à seca, típica da região semiárida, que atinge 6 a $8 \mathrm{~m}$ de altura e até $20 \mathrm{~m}$ de diâmetro de copa, sendo o formato da planta muito parecido com o do umbuzeiro, embora visivelmente maior (NARAIN et al., 2007; CARVALHO et al., 2008).

Os umbu-cajás são frutos do tipo drupa, com formato que varia entre redondo, ovalado e piriforme, de aroma agradável, acidez elevada e $\mathrm{pH}$ entre 2,0 e 3,0. A casca é lisa, pouco espessa e de coloração variando de amarelo a verde-amarelado quando maduro (CARVALHO et al., 2008). Atingem percentual médio de rendimento de polpa de $55,75 \%$ e teor médio de vitamina $\mathrm{C}$ de $17,75 \mathrm{mg} 100 \mathrm{~g}^{-1}$ (LIMA et al., 2002). Os frutos apresentam ainda concentrações relevantes de compostos bioativos, incluindo fenólicos totais, flavonoides e taninos condensados, podendo contribuir com o aporte de antioxidante da dieta (MOREIRA et al., 2012).

Como não existe cultivo comercial de umbucajazeira, os frutos são obtidos de forma extrativista e, consequentemente, seu consumo restringe-se principalmente às regiões onde a planta ocorre espontaneamente.

Dada a peculiaridade de seus atributos sensoriais, os frutos são bastante apreciados para o consumo in natura ou processados na forma de sucos, doces, picolés e sorvetes (MOREIRA et al., 2012). A agroindustrialização do umbu-cajá na forma de geleia representa mais uma alternativa para preservar e agregar valor à fruta, contribuindo para criar alternativas de renda para a população das regiões produtoras, além de divulgar a fruta nos mercados nacional e internacional. Historicamente, as geleias surgiram para preservar as frutas durante o período de entressafra. São produtos de umidade intermediária, obtidos a partir da ebulição da polpa da fruta com açúcar, pectina, ácido e outros ingredientes para obter a consistência adequada (BASU; SHIVHARE, 2010; TOUATI et al., 2014).

As geleias elaboradas com frutas tradicionais, tais como uva, morango e goiaba, são as mais comumente encontradas no mercado, havendo baixa oferta de geleias elaboradas com frutas não tradicionais como o umbu-cajá. É importante considerar que uma das tendências atuais é o desenvolvimento de produtos com baixo teor de açúcar para atender ao percentual da população com restrições ao seu consumo (ABDULLAH;CHENG, 2001). Assim, o desenvolvimento de produtos com sabor similar aos produtos convencionais, apropriados para indivíduos desta categoria, tornase necessário, por meio da substituição da sacarose por adoçantes. Entretanto, a ausência de açúcar em produtos processados altera a retenção de umidade e de outras características como sabor, textura, cor e aroma, tornando difícil o desenvolvimento de novos produtos similares aos convencionais. Assim, ingredientes que dão corpo ao produto devem ser utilizados, visando a substituir o volume e a textura conferidos pelo açúcar (MOSER et al., 2013).

Os polióis são carboidratos hidrogenados que conferem textura aos alimentos, contribuem para o valor nutricional e apresentam características sensoriais desejáveis (LEGAZ; VICENTE, 2005). Dentre os polióis, o xilitol, que tem sido apontado como uma opção em substituição ao açúcar devido ao seu baixo valor calórico, em torno de 2,4 kcal $\mathrm{g}^{-1}$, e com o mesmo poder adoçante da sacarose (ZUMBÉ et al., 2001), apresenta solubilidade em

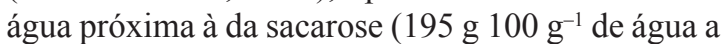
$20^{\circ} \mathrm{C}$ ) e é um excelente agente redutor da atividade de água, o que pode conferir maior conservação ao produto. Este poliol apresenta ainda como vantagens não ocasionar escurecimento do produto por meio de reação de Maillard, ter elevada estabilidade química, alta resistência à cristalização e baixa suscetibilidade à fermentação (CHATTOPADHYAY et al., 2011).

Em vista do exposto, o objetivo deste estudo foi desenvolver geleias dietética e convencional a partir de dois genótipos de umbu-cajá e avaliá-las quanto às características físicas, físico-químicas e sensoriais.

\section{MATERIAL E MÉTODOS}

\section{Obtenção da polpa}

Os frutos de umbu-cajá dos genótipos Preciosa e Suprema foram colhidos no estádio de maturação "de vez", no município de Itaberaba-BA, 12³1'40"S e $40^{\circ} 18^{\prime} 25$ 'O. Foram realizadas três coletas no período de 30 de março a 24 de abril de 2009, em diferentes safras. Os frutos foram transportados para o laboratório, selecionados, lavados e sanitizados em solução de hipoclorito de sódio contendo $50 \mathrm{mg} \mathrm{L}^{-1}$ de cloro ativo, por 15 minutos. A polpa foi obtida por meio de despolpadeira industrial, modelo Compacta, da marca Bonina, com peneira de 2,5 $\mathrm{mm}$ e congelada a $-18^{\circ} \mathrm{C}$ para posterior utilização.

\section{Processamento das geleias}

Para a elaboração das geleias dietética e convencional, utilizou-se de $50 \%$ de sacarose ou xilitol, $50 \%$ de polpa e $0,5 \%$ de pectina cítrica GENU tipo 105 - ATM (alto teor de metoxilação), da marca CP Kelco do Brasil. 
A polpa foi adicionada de sacarose ou xilitol, concentrada até $60^{\circ}$ Brix, em tacho aberto, com agitação manual contínua e adicionada de pectina, previamente dissolvida em água quente, a $80{ }^{\circ} \mathrm{C}$. Quando a geleia atingiu concentração superior a $62{ }^{\circ}$ Brix (dietética) ou $65^{\circ}$ Brix (convencional), o processo foi concluído. A geleia foi envasada em frascos de vidro de $250 \mathrm{~g}$, previamente esterilizados em água a $100^{\circ} \mathrm{C}$, por 30 minutos.

As geleias receberam os seguintes códigos: Geleia Convencional elaborada com o genótipo Suprema - GCS; Geleia Convencional elaborada com o genótipo Preciosa - GCP; Geleia Dietética elaborada com o genótipo Suprema - GDS, e Geleia Dietética elaborada com o genótipo Preciosa - GDP.

Análises físico-químicas da polpa e das geleias

A polpa dos frutos e as geleias foram analisadas quanto ao $\mathrm{pH}$, teor de sólidos solúveis (SS), acidez titulável (AT), todas em triplicatas; umidade e cinzas, em quadruplicata, de acordo com a metodologia descrita pelo Instituto Adolfo Lutz (IAL, 2008). Por espectrofotometria, determinouse o conteúdo de açúcares totais (NELSON, 1944; SOMOGYI, 1945), em quadruplicata. A etapa da hidrólise ácida para os açúcares foi realizada segundo a metodologia do IAL (2008). A análise de proteína foi feita pelo método de Kjeldahl (IAL, 2008), e a de lipídios totais, pelo método de Bligh e Dyer (IAL, 2008), ambas em triplicata.

A cor das geleias foi avaliada utilizando-se do colorímetro Minolta $\AA$, modelo CR400, iluminante D65 e a escala de cor CIELAB. A calibração do aparelho foi realizada por meio de placa de cerâmica branca, utilizando-se do iluminante D65 ( $\mathrm{z}=93,6$; $\mathrm{x}$ $=0,3133 ; \mathrm{y}=0,3195)$. Determinaram-se os valores $\mathrm{L}^{*}, \mathrm{C}^{*} \mathrm{e} \mathrm{h}$, que significam, respectivamente, luminosidade, intensidade da cor/cromaticidade e tonalidade/ângulo de cor.

\section{Análise Sensorial}

As geleias foram avaliadas por 73 provadores, quanto aos atributos aparência, cor, aroma, sabor e textura, utilizando-se da escala hedônica estruturada de nove pontos, sendo os extremos desgostei muitíssimo (1) e gostei muitíssimo (9). Para a intenção de compra, utilizou-se da escala estruturada de cinco pontos, cujos extremos foram: eu certamente compraria (1) e eu certamente não compraria (5) (MEILGAARD et al., 2007). As amostras de geleia foram codificadas com números aleatórios de três dígitos e oferecidas aos provadores com biscoito do tipo água e sal, em blocos balanceados, acompanhadas de água mineral para limpeza do palato.

\section{Delineamento experimental e análise estatística dos resultados \\ O experimento foi conduzido em delineamento} inteiramente casualizado, com três repetições.

Os dados das análises físico-químicas foram submetidos à análise de variância (ANOVA), e contraste entre médias, pelo teste de Tukey, a 5\% de probabilidade.

Os dados do teste de aceitação foram submetidos à análise de variância (ANOVA), contraste entre as médias pelo teste de Tukey, a $5 \%$ de probabilidade, análise de frequência, Mapa de Preferência Interno (MDPREF) e análise de agrupamento, por meio do programa Statistica (STATSOFT, 2007). A análise de frequência dos escores hedônicos para cada amostra de geleia foi realizada de acordo com as seguintes faixas de aceitação:

Rejeição: escores de 1 a 5 , indicam que os consumidores desgostaram da amostra;

Aceitação: escores de 6 a 9, indicam que os consumidores gostaram da amostra.

O MDPREF foi obtido empregando-se a Análise de Componentes Principais. Os dados do teste de aceitação foram organizados em matriz com os tratamentos (formulações) nas linhas e os consumidores nas colunas, e então submetidos à Análise de Componentes Principais (ACP) a partir da matriz de covariâncias.

Foi realizado o agrupamento das diferentes formulações de geleia, utilizando-se de todos os dados de aceitação, independentemente do atributo sensorial avaliado, por meio da distância de Mahalanobis e o método UPGMA(Unweighted PairGroup Method with Arithmetical Average).

As análises foram realizadas utilizando-se dos programas Sisvar, Statistica 7.0 e Genes 1.0.0.

\section{RESULTADOS E DISCUSSÃO}

\section{Caracterização físico-química das polpas e das geleias dietética e convencional}

Os resultados das características físicas e físico-químicas das polpas e das geleias dietéticas e convencional estão apresentados na Tabela 1 . As características das polpas dos dois genótipos avaliados foram muito similares. $\mathrm{O} \mathrm{pH}$ das geleias variou de 2,36 (GCS) a 2,68 (GDS), e a acidez titulável, de $0,66 \%$ (GCP e GDS) a 0,75\% (GDP) de ácido cítrico. Valores maiores de $\mathrm{pH}$ e acidez titulável foram encontrados por Touati et al. (2014) em geleias de apricot, 3,45 e $0,82 \%$, respectivamente, e por Viana et al. (2012) em geleias de mamão com araçá-boi (pH 3,07 a 3,53; e acidez titulável 0,73 a 
$1,53 \%)$.

O teor de sólidos solúveis das geleias variou entre $62,5^{\circ}$ Brix (GDP) e $65,1^{\circ}$ Brix (GCS), sendo os menores teores observados nas geleias dietéticas (GDS e GDP). A proximidade dos valores de sólidos solúveis obtidos para os dois tipos de geleia pode ser explicado pelo fato de o xilitol ser um carboidrato hidrogenado de cinco carbonos, que se comporta similarmente ao açúcar (CHATTOPADHYAY et al., 2011). Embora apresente menor valor calórico, o xilitol possui o mesmo poder adoçante da sacarose, sendo necessário utilizar a mesma quantidade desse ingrediente em relação à sacarose (ZUMBÉ et al., 2001). Valores semelhantes de sólidos solúveis foram verificados por Viana et al. (2012) em geleias convencionais de mamão com araçá-boi (63,92 a $65,25^{\circ}$ Brix) e por Touati et al. (2014) em geleias convencionais de apricot $(64,42 \%)$. Observa-se na literatura que para geleias dietéticas, geralmente são obtidos menores teores de sólidos solúveis do que, os obtidos no presente estudo. Mota (2007) obteve menores teores de sólidos solúveis para geleias dietéticas de amora-preta elaboradas com aspartame (22,59 $\left.{ }^{\circ} \mathrm{Brix}\right)$, esteviosídeo $\left(19,17^{\circ} \mathrm{Brix}\right)$ e ciclamato/ sacarina $\left(14,81^{\circ}\right.$ Brix). Para geleias dietéticas elaboradas com abacaxi, banana e maracujá, adicionadas de sorbitol, Acosta et al (2008) obtiveram teores de sólidos solúveis que variaram de $11,9^{\circ} \mathrm{Brix}$ a $18,8^{\circ}$ Brix. O estudo conduzido por Yuyama et al. (2008) foi o único encontrado na literatura que se assemelha a esse estudo, pois a geleia dietética à base de cubiú e xilitol apresentou $65^{\circ}$ Brix.

Dentre os dados apresentados na Tabela 1, destacam-se os teores de açúcares totais, que foram bem inferiores para as geleias dietéticas (GDS e GDP) em decorrência do uso do xilitol. Os baixos teores de açúcares detectados nas geleias feitas com xilitol contribuem para o desenvolvimento de um produto com baixo valor calórico. Yuyama et al. (2008) também obtiveram baixos teores de açúcares

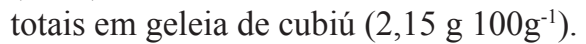

$\mathrm{O}$ teor de umidade das geleias variou entre $26,74 \%$ (GCP) e 29,70\% (GDP), valores semelhantes aos encontrados nos trabalhos de Lago et al. (2006) e Lago-Vanzela et al. (2011) em geleia de jambolão $(29,60 \%)$ e cajá-manga $(29,50 \%)$, respectivamente. Mota (2006) verificou teores de umidade mais elevados (42,84 a 46,44\%) em geleias produzidas a partir de diferentes genótipos de amora-preta. É importante destacar que o teor de umidade está diretamente relacionado com a conservação do produto durante $\mathrm{o}$ armazenamento.

A aparência das polpas e das geleias é a combinação de seus atributos geométricos e atributos cromáticos. Os atributos cromáticos estão associados à cor e foram expressos pelos parâmetros $\mathrm{L}^{*}, \mathrm{C}^{*} \mathrm{e}$ $\mathrm{h} *$ apresentados na Tabela 1 . Os valores obtidos para a coordenada L* variaram de 20,00 (GCS) a 25,06 (GDS), caracterizando a cor das geleias como escuras, uma vez que valores de $\mathrm{L}^{*}$ variam de zero (preto puro) a 100 (branco puro). Os valores observados no presente trabalho foram menores que os obtidos por Martins et al. (2007) para doce em massa de umbu verde e maduro. Os valores de croma $\left(\mathrm{C}^{*}\right)$ do presente estudo variaram de 3,30 (GCD) a 4,44 (GCS) e estão relacionados à intensidade da cor, portanto a geleia GCS apresentou maior valor $\mathrm{C}^{*}$ e coloração mais intensa.

O ângulo de cor ( $\mathrm{h}^{*}$ ) é amplamente usado como ferramenta analítica por ser o atributo pelo qual a cor é percebida como vermelha, amarela, verde ou azul. Assim, os valores de $h^{*}$ variam de 0 (vermelho puro), 90 (amarelo puro), 180 (verde puro) a 270 (azul puro) (RAMALLO;MASCHERONI, 2012). Observase na Tabela 1 que, em média, todos os genótipos apresentam valores de $\mathrm{h} *$ inferiores a 90 (entre 68,53 e 81,39), demonstrando que a cor das geleias está entre o vermelho e o amarelo, ficando mais próxima do amarelo.

\section{Aceitação sensorial}

As médias dos escores de aceitação para as quatro formulações de geleia estão apresentadas na Tabela 2. De forma geral, todas as geleias tiveram boa aceitação para todos os atributos avaliados. Não houve diferença significativa $(\mathrm{p}>0,05)$ quanto à aceitação para o atributo textura; logo, os consumidores não perceberam diferença entre as geleias e classificaramnas entre os termos hedônicos "gostei ligeiramente" e "gostei muito". Esse resultado demonstra que o uso do xilitol resultou em uma geleia dietética similar à convencional para esse atributo, e que a pectina de alto teor de metoxilação foi adequada para elaborar tanto a geleia dietética quanto a convencional, visto que não interferiu na qualidade do gel formado.

Houve diferença significativa $(p \leq 0,05)$ entre as quatro geleias para os atributos cor, aroma e sabor, indicando que esses atributos são responsáveis pela diferenciação entre as amostras.

Para o atributo cor, as geleias GCP e GDS receberam as maiores notas e foram classificadas entre os termos hedônicos "gostei moderadamente" e "gostei muito". As geleias convencionais, elaboradas com os genótipos Suprema e Preciosa (GCS e GCP), foram as mais aceitas para o atributo aroma, sendo que a GCS se destacou também pela maior aceitação em relação ao sabor e foi classificada entre os termos hedônicos "gostei moderadamente" e "gostei muito", para esse atributo. 
As frequências de aceitação e rejeição para as geleias convencionais e dietéticas estão apresentadas na Figura 1. As quatro geleias apresentaram índice de aceitação acima de $80 \%$ para o atributo cor. A geleia convencional Preciosa (GCP) apresentou o maior índice de aceitação para o aroma (84\%), enquanto a geleia dietética Suprema (GDS) foi a que apresentou o maior índice de rejeição para esse atributo (40\%). Para os atributos sabor e textura, os índices de aceitação foram superiores a $78 \%$ para todas as geleias. Destacam-se as geleias convencionais elaboradas com os genótipos Suprema e Preciosa (GCS e GCP), com índices de aceitação de 88\% para o sabor, e a geleia convencional Suprema (GCS), com índice de aceitação de $90 \%$ para a textura.

Para todos os atributos avaliados, os dois primeiros componentes principais (CP1 e CP2) foram superiores a $70 \%$, sendo suficientes para representar a dispersão das geleias, explicando a maior parte da variação dos dados (Figura 2).

Para o atributo cor, os dois componentes principais explicam $84,7 \%$ da variação dos dados, sendo o CP 1 responsável por 51,5\% dessa explicação (Figura 2). A separação espacial das amostras sugere que as quatro geleias apresentam aceitação diferente para esse atributo. Nota-se que a maioria dos consumidores está correlacionada negativamente com o primeiro componente, indicando maior preferência para GCP. Os consumidores correlacionados positivamente com CP1 atribuíram notas mais elevadas para GCS, localizada na parte direita do gráfico. Quanto às geleias dietéticas, a GDS apresentou uma aceitação intermediária, enquanto GDP foi a menos preferida pelos consumidores.

Para o atributo aroma, os dois componentes explicam $82,6 \%$ da variação dos dados, e a posição espacial das amostras indica a formação de três grupos distintos, sendo um formado pela GCS, outro pela GDS e o terceiro grupo formado pelas geleias convencional e dietética elaboradas com a variedade Preciosa (GCP e GDP) (Figura 2). A posição dos consumidores indica maior preferência pelas geleias GCP, GDP e GCS. A geleia dietética Suprema (GDS) foi a menos preferida pelos consumidores para esse atributo.

Para o sabor, verifica-se que os dois componentes principais explicam $78 \%$ da variação dos dados de aceitação (Figura 2). As geleias elaboradas com a variedade Suprema (GCS e GDS) foram preferidas, sendo que os consumidores correlacionados positivamente com CP1 preferiram a geleia dietética (GDS), e os consumidores correlacionados negativamente com CP1 atribuíram notas mais elevadas para a geleia convencional
(GCS). A geleia dietética Preciosa (GDP) apresentou uma aceitação intermediária, enquanto a geleia convencional Preciosa (GCP) foi a menos aceita pelos consumidores para esse atributo.

Em relação ao atributo textura, os consumidores correlacionados positivamente com CP1 atribuíram notas mais elevadas para a geleia convencional Suprema (GCS), e os correlacionados negativamente com CP2 preferiram a geleia convencional Preciosa (GCP) (Figura 2). As geleias dietéticas foram preferidas por alguns consumidores posicionados na parte superior do gráfico $\left(1^{\circ}\right.$ e $2^{\circ}$ quadrantes) e tiveram, portanto, menor aceitação para esse atributo.

Por meio de uma análise global do mapa de preferência interno, não foi possível identificar a geleia de maior aceitação para todos os atributos avaliados, uma vez que a direção da preferência apontou geleias distintas para cada atributo avaliado. A geleia convencional Suprema (GCS) foi preferida para os atributos aroma, sabor e textura, enquanto a geleia convencional Preciosa (GCP) foi preferida para os atributos cor, aroma e textura. A geleias dietéticas foram as menos preferidas.

Ao realizar a análise de agrupamento, considerando todos os atributos avaliados, verificase que os consumidores diferenciaram as amostras quanto à aceitação. Houve a formação de três grupos, sendo o primeiro formado pela geleia GCP, o segundo pelas geleias dietéticas (GDP e GDS) e o terceiro pela geleia GCS. Assim, de forma global, as geleias dietéticas foram consideradas semelhantes, e as geleias convencionais diferenciaram-se entre si quanto à aceitação sensorial.

Quantoàintenção de compra dos consumidores, agrupando-se as categorias "certamente compraria" e "possivelmente compraria", 70\% dos consumidores indicaram que comprariam a formulação GCS; 56\% comprariam GCP, enquanto $56 \%$ e $48 \%$ comprariam as geleias GDS e GDP, respectivamente, caso essas fossem comercializadas (Figura 4). Considerando o percentual da população que consome alimentos dietéticos, esse resultado aponta para um potencial mercado, não só para a geleia convencional, mas também para a dietética, visando atender à demanda de uma faixa da população com restrição ao uso da sacarose, em busca deste tipo de produto.

Yuyama et al. (2008) obtiveram a aceitabilidade de $85,62 \%$ para a geleia de cubiú elaborada com xilitol e $81,05 \%$ para as geleias com sacarose. Os autores verificaram que não houve diferença significativa, em nível de 5\%, confirmando a similaridade entre as geleias. 

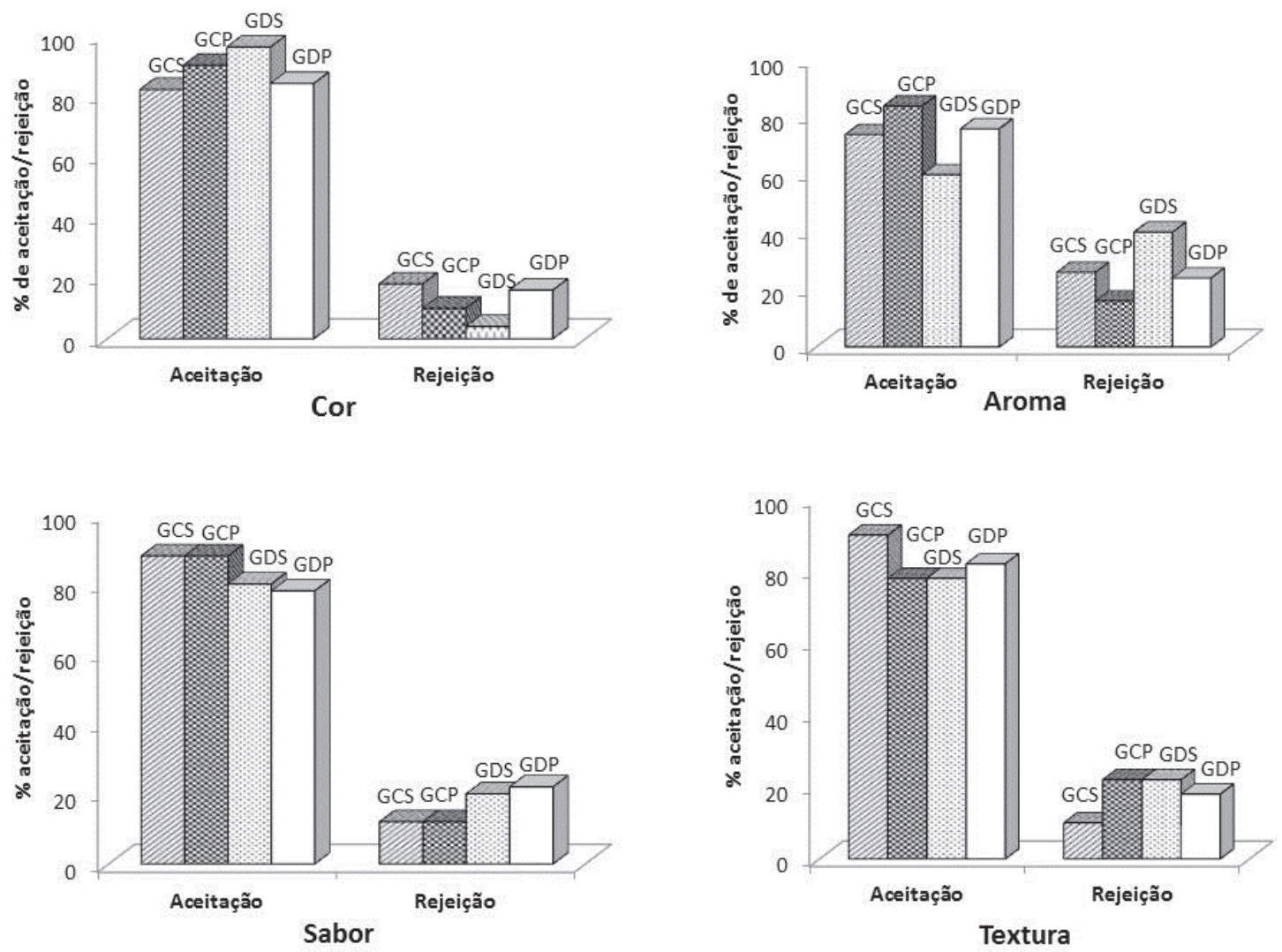

FIGURA 1- Frequências de aceitação e rejeição pelos consumidores para as quatro formulações de geleia de umbu-cajá referentes a cada atributo sensorial avaliado. GCS- geleia convencional elaborada com o genótipo Suprema; GCP- geleia convencional elaborada com o genótipo Preciosa; GDS- geleia dietética elaborada com o genótipo Suprema, e GDP-geleia dietética elaborada com o genótipo Preciosa. 


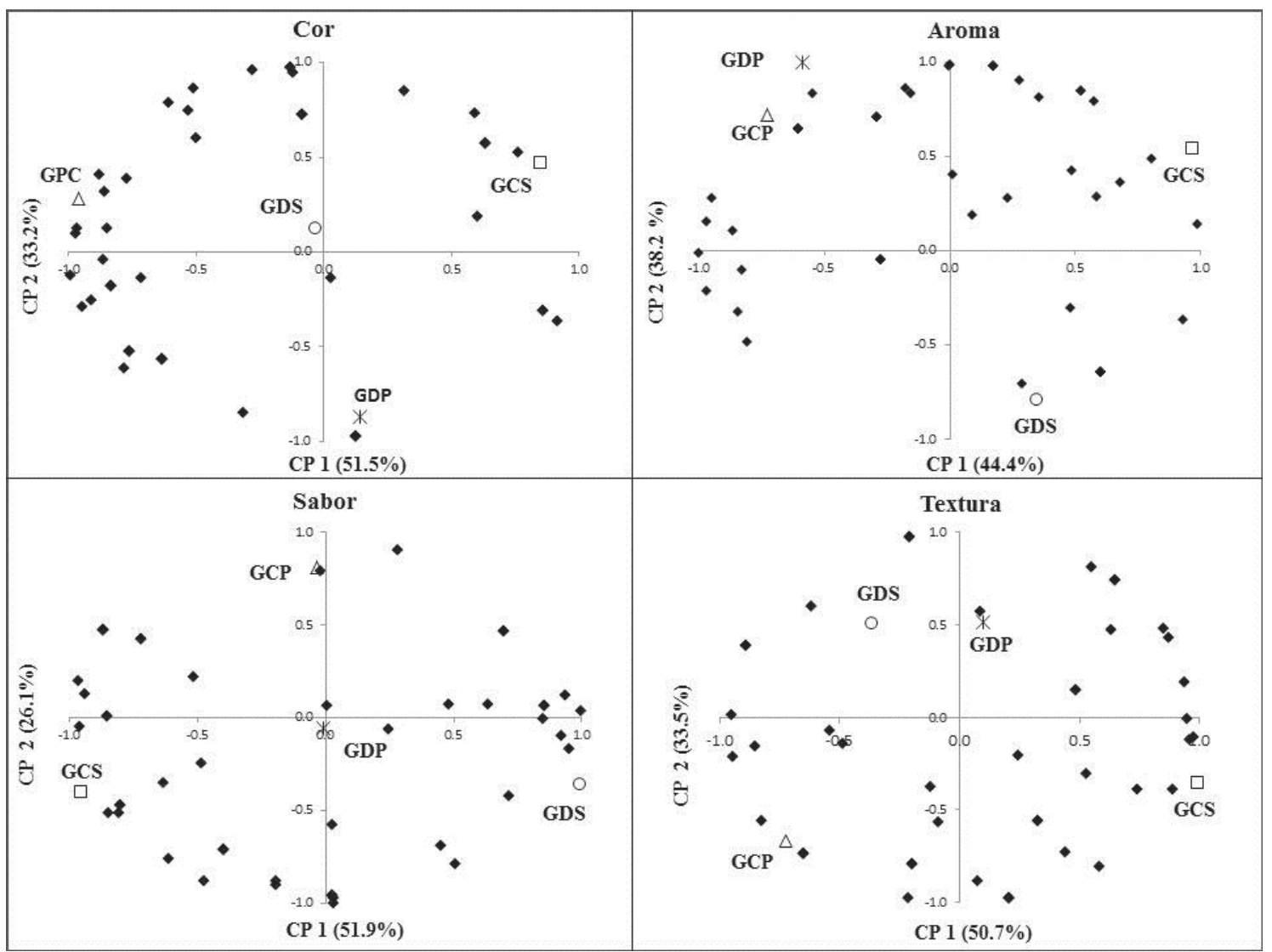

FIGURA 2- Mapa de Preferência Interno de geleia de umbu-cajá em relação aos atributos sensoriais avaliados. GCS- geleia convencional elaborada com o genótipo Suprema; GCP- geleia convencional elaborada com o genótipo Preciosa; GDS- geleia dietética elaborada com o genótipo Suprema, e GDP- geleia dietética elaborada com o genótipo Preciosa.

TABELA 1- Características físico-químicas da polpa e das geleias de umbu-cajá convencional e dietética ${ }^{(a)}$.

\begin{tabular}{lcccccc}
\hline \multirow{2}{*}{ Características avaliadas } & & & \multicolumn{3}{c}{ Geleias avaliadas $^{(\mathrm{b})}$} \\
\cline { 5 - 7 } & PS $^{(\mathrm{c})}$ & PP $^{(\mathrm{d})}$ & GCS & GCP & GDS & GDP \\
\hline $\mathrm{pH}$ & 2,50 & 2,50 & $2,36 \mathrm{~d}$ & $2,42 \mathrm{c}$ & $2,68 \mathrm{a}$ & $2,57 \mathrm{~b}$ \\
Acidez titulável (g ácido cítrico $\left.100 \mathrm{~g}^{-1}\right)$ & 2,70 & 2,60 & $0,73 \mathrm{ab}$ & $0,66 \mathrm{bc}$ & $0,66 \mathrm{c}$ & $0,75 \mathrm{a}$ \\
Sólidos Solúveis ( ${ }^{\circ}$ Brix) & 10,0 & 10,0 & $65,10 \mathrm{a}$ & $65,00 \mathrm{ab}$ & $62,80 \mathrm{bc}$ & $62,50 \mathrm{c}$ \\
Açúcares totais $(\%$ de glicose) & - & - & $57,05 \mathrm{a}$ & $56,28 \mathrm{~b}$ & $4,56 \mathrm{c}$ & $4,65 \mathrm{c}$ \\
Umidade $(\%)$ & - & - & $28,75 \mathrm{ab}$ & $26,74 \mathrm{c}$ & $28,27 \mathrm{~b}$ & $29,70 \mathrm{a}$ \\
$\mathrm{L}^{*(\mathrm{e})}$ & - & - & $20,00 \mathrm{c}$ & $23,89 \mathrm{~b}$ & $25,06 \mathrm{a}$ & $24,14 \mathrm{~b}$ \\
$\mathrm{C}^{*(\mathrm{f})}$ & - & - & $4,44 \mathrm{a}$ & $3,30 \mathrm{c}$ & $3,42 \mathrm{c}$ & $3,58 \mathrm{~b}$ \\
$\mathrm{~h}^{*(\mathrm{~g})}$ & - & - & $81,39 \mathrm{~ns}$ & $70,08 \mathrm{~ns}$ & $68,53 \mathrm{~ns}$ & $72,85 \mathrm{~ns}$ \\
\hline
\end{tabular}

(a) Médias seguidas por letras iguais, na linha, não diferem entre si, ao nível de $5 \%$ de significância, pelo teste de Tukey. ${ }^{(b)}$ GCS- geleia convencional elaborada com o genótipo Suprema; GCP- geleia convencional elaborada com o genótipo Preciosa; GDS- geleia dietética elaborada com o genótipo Suprema, e GDP- geleia dietética elaborada com o genótipo Preciosa; ${ }^{(\mathrm{c}} \mathrm{PS}-$ Polpa do genótipo Suprema; ${ }^{(\mathrm{d})}$ PP- polpa do genótipo Preciosa; ${ }^{(e)} \mathrm{L}^{*}$ - luminosidade; ${ }^{\left({ }^{\mathrm{f}}\right)} \mathrm{C}^{*}$ - intensidade da cor/saturação; $\mathrm{h}^{*(\mathrm{~g})}$ - tonalidade/ângulo de cor. 
TABELA 2- Escores hedônicos obtidos pelo teste de aceitação em relação aos atributos avaliados ${ }^{(a)}$.

\begin{tabular}{lcccc}
\hline \multicolumn{1}{c}{ Geleias $^{(\mathrm{b})}$} & Cor & Aroma & Sabor & Textura \\
\hline GCS & $6.88 \mathrm{~b}$ & $6.52 \mathrm{a}$ & $7.22 \mathrm{a}$ & $7.22 \mathrm{a}$ \\
GCP & $7.60 \mathrm{a}$ & $6.78 \mathrm{a}$ & $6.56 \mathrm{ab}$ & $6.94 \mathrm{a}$ \\
GDS & $7.30 \mathrm{ab}$ & $5.90 \mathrm{~b}$ & $6.80 \mathrm{ab}$ & $6.80 \mathrm{a}$ \\
GDP & $6.92 \mathrm{~b}$ & $6.20 \mathrm{ab}$ & $6.44 \mathrm{~b}$ & $6.82 \mathrm{a}$ \\
\hline
\end{tabular}

(a) Médias seguidas por letras iguais na mesma coluna não diferem entre si, ao nível de 5\% de significância, pelo teste de Tukey. ${ }^{(b)}$ GCSgeleia convencional elaborada com o genótipo Suprema; GCP- geleia convencional elaborada com o genótipo Preciosa; GDS- geleia dietética elaborada com o genótipo Suprema, e GDP- geleia dietética elaborada com o genótipo Preciosa.

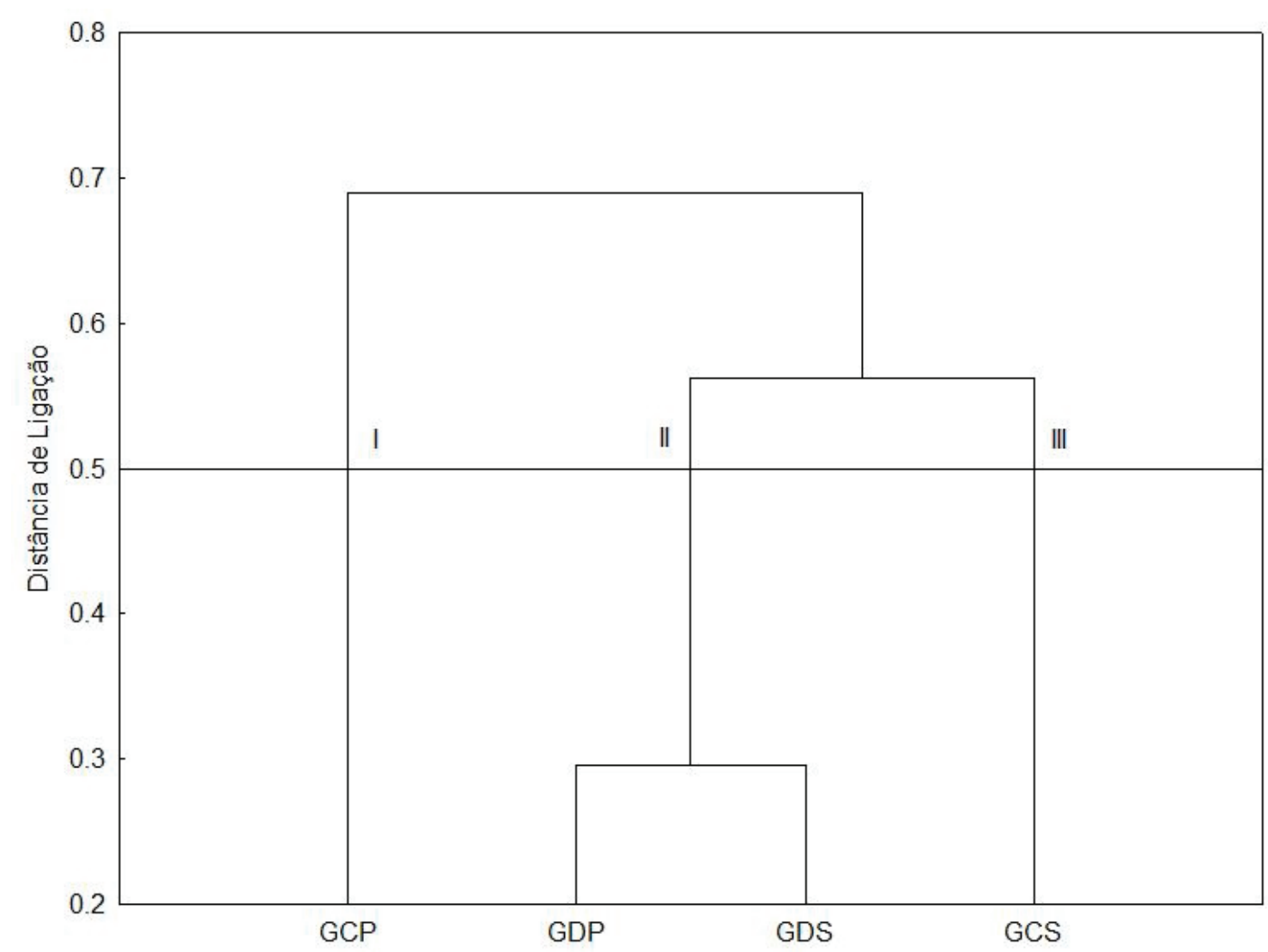

FIGURA 3- Análise de agrupamento do teste de aceitação das geleias dietéticas e convencionais de umbucajá. GCS- geleia convencional elaborada com o genótipo Suprema; GCP- geleia convencional elaborada com o genótipo Preciosa; GDS- geleia dietética elaborada com o genótipo Suprema, e GDP- geleia dietética elaborada com o genótipo Preciosa. 


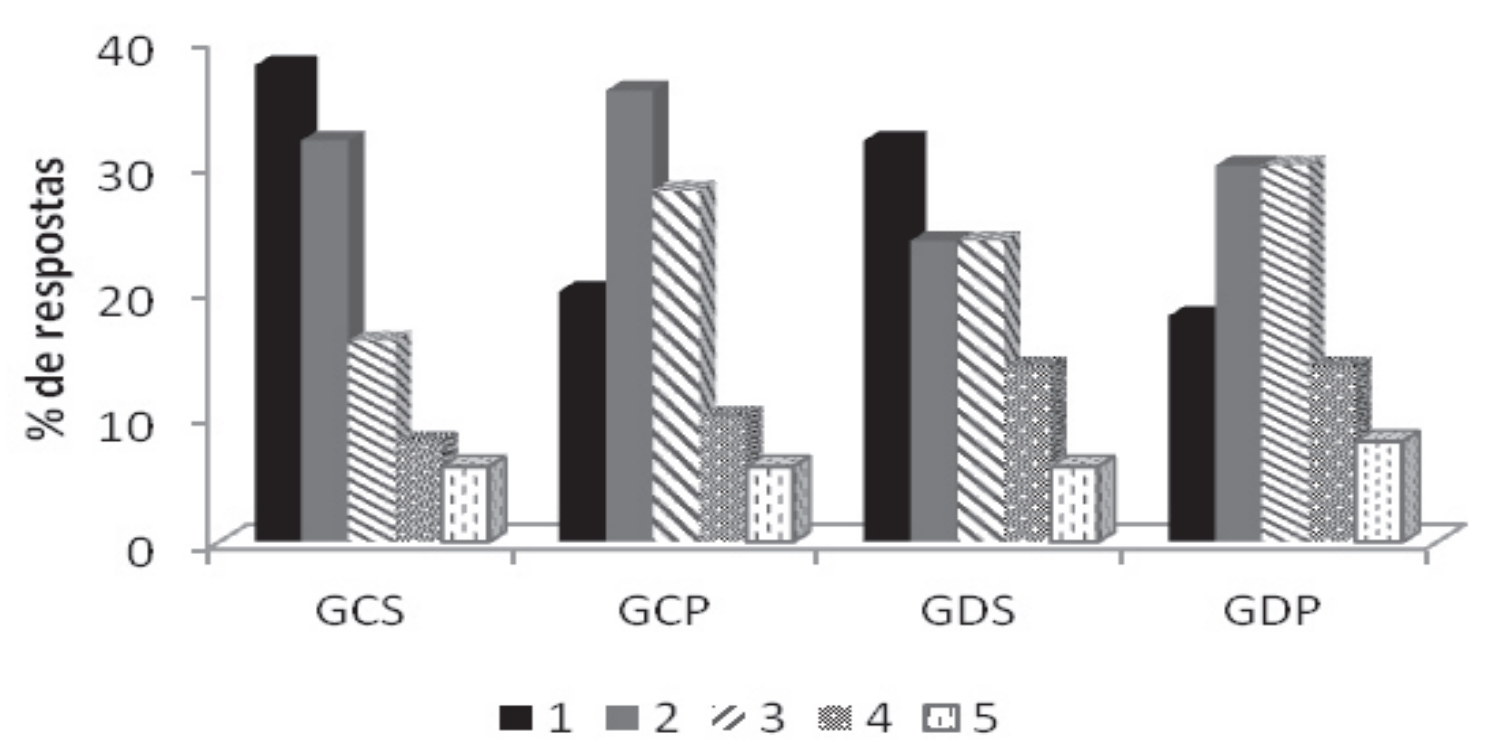

FIGURA 4- Intenção de compra dos julgadores para as geleias de umbu-cajá convencional e dietética. 1 Eu certamente compraria; 2 - Eu provavelmente compraria; 3 - Tenho dúvida se compraria ou não; 4 - Eu provavelmente não compraria; 5 - Eu certamente não compraria; GCS- geleia convencional elaborada com o genótipo Suprema; GCP- geleia convencional elaborada com o genótipo Preciosa; GDS- geleia dietética elaborada com o genótipo Suprema, e GDP- geleia dietética elaborada com o genótipo Preciosa.

\section{CONCLUSÃO}

Os frutos de umbu-cajá dos genótipos Suprema e Preciosa foram promissores para a produção de geleias convencional e dietética. De maneira geral, as geleias adoçadas com sacarose ou xilitol, produzidas com ambos os genótipos, apresentaram características físico-químicas similares e boa aceitação sensorial.

O produto apresenta potencial de mercado para atender públicos distintos, sejam eles consumidores comuns, sejam pessoas diabéticas ou em dieta com restrição calórica.

\section{REFERÊNCIAS}

ABDULLAH, A. CHENG, C. T. Optimization of reduced calorie tropical mixed fruits jam. Food Quality and Preference, Amsterdam, v.12, n.1, p.63-68, 2001.

ACOSTA, O; VÍQUEZ, F; CUBERO, E. Optimisation of low calorie mixed fruit jelly by response surface methodology. Food Quality and Preference, Amsterdam, v.19, p.79-85, 2008.
BASU, S.; SHIVHARE, U. S. Rheological, textural, microstructural and sensory properties of mango jam. Journal of Food Engineering, Oxford, v.100, p.357-365, 2010.

CARVALHO, P. C. L.; RITZINGER, R.; SOARESFILHO, W. S.; LEDO, C. A. S. Características morfológicas, físicas e químicas de frutos de populações de umbu-cajazeira no Estado da Bahia. Revista Brasileira de Fruticultura, Jaboticabal, v.30, n.1, p.140-147, 2008.

CHATTOPADHYAY, S; RAYCHAUDHURI, U.; CHAKRABORTY, R. Artificial sweeteners - a review. Journal of Food Science and Technology, Mysore, v.51, n.4, p.611-621, 2011.

IAL - Instituto Adolfo Lutz. Métodos físicoquímicos para análise de alimentos. 4.ed. São Paulo, 2008. 1020 p. 
LAGO, E. S.; GOMES, E.; SILVA, R. Produção de geleia de jambolão (Syzygium cumini lamarck): processamento, parâmetros físico-químicos e avaliação sensorial. Ciência e Tecnologia de Alimentos, Campinas, v.26, n.4, p.847-852, 2006.

LAGO-VANZELA, E. S; RAMIN, P.; GUEZUMSZA, M.A.; SAMTPS, G. V.; GOMES, E.; SILVA, R. Caracterização química e sensorial de geléia da casca e polpa de cajá-manga (Spondias cytherea Sonn.). Ciência e Tecnologia de Alimentos, Campinas, v.31, n.2, p.398-405, 2011.

LEGAZ, M.E.; VICENTE, C. Carbohydrates: sugar alcohols. In: WORSFOLD, P.J.; TOWNSHEND A.; POOLE, C. Encyclopedia of analytical science. 2.ed. London: Academic Press, 2005. p.427-439.

LIMA, E. D. P. A; LIMA, C. A. A.; ALDRIGUE, M.L.; GONDIM, P.J.S. Caracterização física e química dos frutos da umbu-cajazeira (Spondias spp) em cinco estádios de maturação, da polpa congelada e néctar. Revista Brasileira de Fruticultura, Jaboticabal, v.24, n.2, p. 338-343, 2002.

MARTINS, M. L. A; BORGES, S. V.; DELIZA, R.; CAStro, F. T.; CAVAlCANTE, N. D. Características de doce em massa de umbu verde e maduro e aceitação pelos consumidores. Pesquisa Agropecuária Brasileira, Brasília, v.42, n.9, p.13291333, 2007.

MEILGAARD, G.K.; CIVILLE, G.V.; CARR, B.I. Sensory evaluation techniques: marketing and $R$ $\&$ D approaches. $4^{\text {th }}$ ed. Boca Raton: CRC Press, 2007. p.141-172.

MOREIRA, A. C. C. G.; NASCIMENTO, J. D. M; ANDRADE, R. A. M. S.; MACIEL, M. I. S; MELO, E. A. Fitoquímicos bioativos em frutos de genótipos de cajá-umbuzeiras. Alimentos e Nutrição, Araraquara, v. 23, n. 2, p. 235-241, 2012.

MOSER, P.; CORNELIO, M.L.; TELIS, V.R.N. Influence of the concentration of polyols on the rheological and spectral characteristics of guar gum. Food Science and Technology, Amsterdam, v.53, p.29-36, 2013.

MOTA, R. V.Características químicas e aceitabilidade de geléias de amora-preta de baixo teor de sólidos solúveis. Brazilian Journal of Food Technology, Campinas, v.10, n.2, p.116-121, 2007.
MOTA, R. V. Caracterização física e química de geleia de amora-preta. Ciência e Tecnologia de Alimentos, Campinas, v.26, n.3, p.539-543. 2006.

NARAIN, N.; GALVÃO, M. S.; MADRUGA, S. M. Volatile compounds captured through purge and trap technique in cajá-umbu (Spondias sp.) fruits during maturation. Food Chemistry, London, v.102, n.3, p.726-731, 2007.

NELSON, N. A photometric adaptation of the Somogyi method for the determination of glucose. The Journal of Biological Chemistry, Baltimore, v.153, n.2, p.375-380, 1944.

RAMALLO, L. A.; MASCHERONI, R. H. Quality evaluation of pineapple fruit during drying process. Food and Bioproducts Processing, Christchurch, v. 90, p. 275-283, 2012.

SOMOGYI, M. A new reagent for the determination of sugar. The Journal of Biological Chemistry, Baltimore, v.160, n.1, p.61-68, 1945.

STATSOFT SOUTH AMERICA. Data analysis software system. Version 7. Disponível em: $<\underline{\mathrm{http}}: / /$ www.statsoft.com.2007>. Acesso em: 10/11/2010.

TOUATI, N.; TARAZONA-DÍAZ, M. P., AGUAYO, E., LOUAILECHE, H. Effect of storage time and temperature on the physicochemical and sensory characteristics of commercial apricot jam. Food Chemistry, London, v.145, p.23-27, 2014.

VIANA, E. S.; JESUS, J. L.; REIS, R. C.; FONSECA, M. D.; SACRAMENTO, C. K. Caracterização físico-química e sensorial de geleia de mamão com araçá-boi. Revista Brasileira de Fruticultura, Jaboticabal, v.34, n.4, p.1154-1164, 2012.

YUYAMA, L. K. O.; PANTOJA, L.; MAEDA, R. N.; AGUIAR, J.P.L.; SILVA, S.B. Development and acceptability of a low calorie cubiu (Solanum sessiliflorum Dunal) Jam. Ciência e Tecnologia de Alimentos, Campinas, v.28, n.4, p.929-934, 2008.

ZUMBÉ, A., LEE, A., STOREY, D. Polyols in confectionery: the route to sugar free, reduced sugar and reduced calorie confectionery. British Journal of Nutrition, Southampton v. 85, n.1, p 31-45. 2001. 